PACS 32.80.Rm; 05.45.+b;

УДК 539.142, 539.184

\title{
SENSING NEW LASER-ELECTRON-NUCLEAR EFFECTS IN DIATOMIC MOLECULES: $\mathrm{H}^{79} \mathrm{Br}$
}

\author{
S. V. Malinovskaya \\ Odessa National Polytechnical University, P.O.Box 108, Odessa-9, 65009, Ukraine \\ E-mail: glushkov@paco.net
}

\begin{abstract}
SENSING THE NEW LASER-ELECTRON-NUCLEAR EFFECTS IN DIATOMIC MOLECULES: $\mathrm{H}^{79} \mathrm{Br}$
\end{abstract}

\section{S. V. Malinovskaya}

New theoretical scheme developed and used for sensing new laser-electron nuclear effects in diatomics, which can be used for creation of the new type sensors for tasks of nuclear technologies. It is carried out calculating the vibration-rotation-nuclear transition probabilities in a case of the emission and absorption spectrum of nucleus ${ }^{79} \mathrm{Br}\left(\mathrm{E}_{\gamma}^{(0)}=217 \mathrm{keV}\right)$ linked with molecule $\mathrm{H}^{79} \mathrm{Br}$.

Key words: sensing laser-electron-nuclear effects and nuclear sensors, vibration-rotationnuclear transitions probability, molecule of $\mathrm{HBr}$

\section{Резюме \\ ДЕТЕКТУВАННЯ НОВИХ ЛАЗЕРНИХ ЕЛЕКТРОН-ЯДЕРНИХ ЕФЕКТІВ У ДВОАТОМНИХ МОЛЕКУЛАХ: $\mathrm{H}^{79} \mathrm{Br}$}

\section{С. В. Малиновська}

Нова теоретична схема розвинута та використана у задачі детектування нових лазерних електрон-ядерних ефектів у двоатомних молекулах, які можуть бути використані при побудові нових типів сенсорів для задач ядерних технологій.. Виконано розрахунок імовірностей коливно-обертально-ядерных переходів для спектру випромінювання і поглинення ядра ${ }^{79} \mathrm{Br}\left(\mathrm{E}_{\gamma}^{(0)}=217 \mathrm{keV}\right)$ у молекулі $\mathrm{H}^{79} \mathrm{Br}$.

Ключові слова: детектування лазерних електрон-ядерних ефектів та ядерні сенсори, імовірність коливально-обертально-ядерних переходів, молекула $\mathrm{HBr}$ 


\section{Резюме \\ ДЕТЕКТИРОВАНИЕ НОВЫХ ЛАЗЕРНЫХ ЭЛЕКТРОН-ЯДЕРНЫХ ЭФФЕКТОВ В ДВУХАТОМНЫХ МОЛЕКУЛАХ: $\mathrm{H}^{79} \mathrm{Br}$}

\section{С. В. Малиновская}

Новая теоретическая схема развита и использована в задаче детектирования новых лазерных электрон-ядерных эффектов в двухатомных молекулах, которые могут быть использованы при создании новых типов сенсоров для задач ядерных технологий. Выполнен расчет вероятностей колебательно- вращательно- ядерных переходов для спектра излучения и поглощения ядра ${ }^{79} \mathrm{Br}\left(\mathrm{E}_{\gamma}^{(0)}=217 \mathrm{keV}\right)$ в молекуле $\mathrm{H}^{79} \mathrm{Br}$.

Ключевые слова: детектирование лазерных электрон-ядерных эффектов и ядерные сенсоры, вероятность колебательно-вращательно-ядерных переходов, молекула $\mathrm{HBr}$

This paper goes on our studying co-oprative new laser-electron nuclear effects in atomic and molecular systems and devoted to carrying out and using new theoretical scheme for sensing laser vibrationritation-nuclear effects in diatomic molecules. In last years with appearance of the intensive neutron pensils, powerful laser sources especial interest attracts a class of problems, connected with the photo excitation of molecules, semiconductors and solids by neutrons, photons, electrons (c.f.[1-17]). Especial interest attracts carrying out sensing schemes and devices for their manifestation and observation. We will consider a consistent approach to description and further sensing a new class dynamical laserelectron-nuclear effects in molecular systems, in particular, the nuclear emission or absorption spectrum of the diatomic molecule. This spectrum contains a set of electron-vibration-rotation satellites, which are due to an alteration of the state of system under interaction with photon. $[4,11]$. A mechanism of forming satellites in the molecule is as follows: in a case of the loose electron shell a shaking of the shell resulting from the interaction between the nucleus and $\gamma$ quantum. The well known example is the Szilard-Chalmers effect (molecular dissociation because of the recoil during radiating gamma quantum with large energy). The satellite spectrum is much enriched and transitions between the fine structure components, $0-0$ transitions and transitions, which do not involve a change in the electron configuration, can be considered. In the molecule a spectrum is naturally more complicated in comparison with atom. Under nuclear $\gamma$-quantum emission or absorption there is a change of the electron (vibration-rotation) states. New consistent, quantum- mechanical approach to calculation of the electron-nuclear $\gamma$ transition spectra (set of vibration-rotational satellites in molecule) of nucleus in molecule has been proposed in ref.[11,14] and based on the using the Dunham model potential approximation for potential curves of the diatomic molecules [18-20]. There have been evaluated the vibration-rotation-nuclear transition probabilities for the emission and absorption spectrum of nucleus ${ }^{127} \mathrm{I}\left(\mathrm{E}_{\gamma}^{(0)}=203 \mathrm{keV}\right)$ in molecule of $\mathrm{H}^{127} \mathrm{I}$. Another very interesting example is nuclear transition with $\gamma$ energy $217 \mathrm{KeV}$ in nucleus of ${ }_{35} \mathrm{Br}_{44}^{79}$, linked with molecule of $\mathrm{H}^{79} \mathrm{Br}$.

In ref.[11-14], it has been developed a new consistent theoretical approach to calculation of a structure of the gamma transitions (probability of transition) or spectrum of the gamma satellites because of the changing the electron or electron-vibration-rotational states in atomic and diatomic systems under the gamma quantum radiation (absorption). Let us describe in bried the key moemnts of the molecular version of the approach. In adiabatic approximation a wave function of molecule is multiplying the electronic wave function and wave function of nuclei: $\psi\left(\mathrm{r}_{\mathrm{e}}\right) \psi\left(\mathrm{R}_{1}, \mathrm{R}_{2}\right)$. Hamiltonian of interaction of the gamma radiation with system of nucleons for the first nucleus can be expressed through the co-ordinates of nucleons $r_{n}$ ' in a system of the mass centre of the first nucleus $[13,14]$ :

$$
H\left(r_{n}\right)=H\left(r_{n}^{\prime}\right) \exp \left(-i k_{\gamma} R_{1}\right)
$$

where $\mathrm{kg}$ is a wave vector of the gamma quantum. The matrix element for transition from initial state "a" to final state " $b$ " is presented as follows $[3,6]$ :

$$
\begin{gathered}
<\Psi_{b}^{*}\left(r_{n}\right)\left|H\left(r_{n}\right)\right| \Psi_{a}\left(r_{n}\right)> \\
\bullet<\Psi_{b}^{*}\left(r_{e}\right) \Psi_{b}^{*}\left(R_{1}, R_{2}\right)\left|e^{-i k_{\gamma} R_{1}}\right| \Psi_{a}\left(r_{e}\right) \Psi_{a}\left(R_{1}, R_{2}\right)>
\end{gathered}
$$

The first multiplier in (1) is defined by the gamma transition of nucleus and is not dependent upon an internal structure of molecule in a good approxi- 
mation. The second multiplier is a matrix element of transition of the molecule from from initial state "a" to final state "b":

$$
\begin{gathered}
M_{b a}=<\Psi_{b}^{*}\left(r_{e}\right) \mid \Psi_{a}\left(r_{e}\right)> \\
\bullet<\Psi_{b}^{*}\left(R_{1}, R_{2}\right)\left|e^{-i k_{y} R_{1}}\right| \Psi_{a}\left(R_{1}, R_{2}\right)>
\end{gathered}
$$

The expression (3) gives a general formula for calculation of the probability of changing internal state of molecule under absorption or emitting gamma quantum by nucleus of the molecule and defines an amplitude of the corresponding gamma satellites. Their positions are fully determined by the energy and pulse conserving laws as follows:

$$
\begin{gathered}
\pm E_{\gamma}+E_{a}+(1 / 2) M v_{0}^{2}= \pm E_{\gamma}^{(0)}+E_{b}+(1 / 2) M v^{2} \\
M v_{0} \pm \hbar k_{\gamma}=M v
\end{gathered}
$$

Here $M$ is the molecule mass, $\mathrm{v}_{0}$ and $\mathrm{v}$ are velocities of molecule before and after interaction of nucleus with $\gamma$ quantum, $E_{a}$ and $E_{b}$ are the energies of molecule before and after interaction, $\mathrm{E} \gamma$ is an energy of nuclear transition. Then an energy of the $\gamma$ satellite is as follows from (4):

$$
E_{\gamma}=E_{\gamma}^{(0)}+\hbar k_{\gamma} v_{0} \pm R_{o m} \pm\left(E_{b}-E_{a}\right)
$$

Here $R_{o m}$ is an energy of recoil: $R_{o m}=\left[\left(\mathrm{E}^{(0)}\right]^{2 /}\right.$ $2 \mathrm{Mc}^{2}$. It is well known (c.f. $\left.[3,6]\right)$ that the practical interest are presented only transitions between vibration-rotational levels of the ground electron state, including transitions into continuum with further molecular dissociation. The matrix element for these transitions is

$$
M_{b a}=<\Psi_{b}^{*}\left(R_{1}, R_{2}\right)\left|e^{-i k_{\gamma} R_{1}}\right| \Psi_{a}\left(R_{1}, R_{2}\right)>
$$

The values of energy, accepted by vibration and rotational degrees of freedom of the molecule are as follows: $\varepsilon_{\mathrm{vib}} \approx \mathrm{v} \hbar \omega=\mathrm{R}_{\mathrm{om}}\left(\mathrm{m}_{2} / \mathrm{m}_{1}\right), \varepsilon_{\mathrm{rot}} \approx \mathrm{BJ}^{2}=\mathrm{R}_{\mathrm{om}}\left(\mathrm{m}_{2} / \mathrm{m}_{1}\right)$. The simple adequate model for definition of the rotational motion is the rigid rotator approximation. In this approximation the wave functions with definite values of quantum numbers $\mathrm{J}, \mathrm{K}$ are the eigen functions of the angle momentum operator, i.e.: $\psi\left(\mathrm{R}_{1}, \mathrm{R}_{2}\right)=\mathrm{Y}_{\mathrm{J}, \mathrm{K}}(\theta, \varphi)$. In a case of the vibration motion the wave functions with definite value of the vibration quantum number are numerically found by solving the corresponding Schrödinger equation with potential, which is chosen in the Dunham-like form [18-20]. Such an approximation is surely more consistent than the harmonic oscillator one as example. The harmonic oscillator wave functions were used for estimating matrix elements of the vibration- nuclear transitions in ref. [3]. In general the matrix element of the vibration-rotation-nuclear transition can be written as follows:

$$
\begin{gathered}
M_{J_{b}, K_{b} ; J_{a}, K_{a}}^{v_{b}, v_{a}}=(4 \pi)^{1 / 2}\left[\left(2 \mathrm{~J}_{\mathrm{a}}+1\right)\left(2 \mathrm{~J}_{\mathrm{b}}+1\right)\right]^{1 / 2}(-1)^{\mathrm{K}}{ }_{\mathrm{b}} \\
\sum_{l=J_{b}-J_{a} l}^{J_{a}+J_{b}} i^{l}\{2 l+1\}^{1 / 2}<\Psi_{v_{b}}\left|(\pi / 2 a)^{1 / 2} J_{l+1 / 2}(a)\right| \Psi_{v_{a}}> \\
\left(\begin{array}{ccc}
J_{a} & J_{b} & l \\
0 & 0 & 0
\end{array}\right)_{m=-l}^{+l} Y_{l m}^{*}\left(\begin{array}{ccc}
J_{a} & J_{b} & l \\
k_{a} & -k_{b} & m
\end{array}\right) \\
a=\left(E \gamma^{(o) / \hbar c} /\left(m_{2} / M\right) R^{*}\left(1+Q /\left[(m)^{1 / 2} R^{*}\right]\right.\right.
\end{gathered}
$$

Here $Q=\left(R-R_{o}\right)(m)^{1 / 2}, m=m_{l} m_{2} / M$ is the reduces mass of the molecule, $\mathrm{m}_{1}$ and $\mathrm{m}_{2}$ are the masses of nuclei. The co-ordinate of mass centre of the first nucleus relatively the molecule mass centre is defined by expression:

$$
\begin{gathered}
R_{1}=-\left(m_{2} / M\right) R=-\left(m_{2} / M\right)\left[R_{o}+Q /(m)^{1 / 2}\right]= \\
=-\left(m_{2} / M\right) R_{o}-\left(m_{2} / m_{1} M\right)^{1 / 2} Q .
\end{gathered}
$$

The corresponding probability can be written in the following form:

$$
\begin{gathered}
P_{J_{b} J_{a}}^{v_{b} v_{a}}=\left(2 \mathrm{~J}_{\mathrm{b}}+1\right) \times \\
\times \sum_{l=\left|J_{b}-J_{a}\right|}^{J_{a}+J_{b}}\{2 l+1\}\left|<\Psi_{v_{b}}\right|(\pi / 2 a)^{1 / 2} J_{l+1 / 2}(a)\left|\Psi_{v_{a}}>\right|^{2} \times \\
\times\left(\begin{array}{ccc}
J_{a} & J_{b} & l \\
0 & 0 & 0
\end{array}\right)^{2}(9)
\end{gathered}
$$

We have carried out the calculation of the probabilities for vibration-rotation-nuclear transitions from initial state with $\mathrm{v}_{\mathrm{a}}=0, \mathrm{~J}_{\mathrm{a}}=0$ in a case of the emission and absorption spectrum of nucleus of ${ }_{35} \mathrm{Br}_{44}^{79}$, linked with molecule of $\mathrm{H}^{79} \mathrm{Br}$ in the ground electron state $\mathrm{X}^{1} \Sigma$ (molecular parameters: $\mathrm{R}_{\mathrm{o}}=1,414 \AA$, $\left.v_{\mathrm{e}}=2649 \mathrm{~cm}^{-1}, \mathrm{~B}=8,465 \mathrm{~cm}^{-1}\right)$. The recoil energy for this molecule is $0,18 \mathrm{eV}$. Parameters, which define excitation of vibrations and rotations of this molecule because of the recoil, are as follows: $\mathrm{a}_{0}=1,35$ and $\varepsilon_{\mathrm{o}}=5.72 \cdot 10^{-2}$ In figure 1 we present the calculated spectrum of emission and adsorption of nucleus ${ }^{79} \mathrm{Br}$ in molecule of $\mathrm{H}^{79} \mathrm{Br}$ (the initial state of molecule: $\mathrm{v}_{\mathrm{a}}=0, \mathrm{~J}_{\mathrm{a}}=0$ ). Let us note that the calculated spectrum is qualitatively similar to analogous one for nucleus ${ }^{127} \mathrm{I}$ in molecule of $\mathrm{H}^{127} \mathrm{I}$ [14]. The values for probabilities, calculated within the Dunham model potential approximation for potential curve $[9,10]$, differ from the corresponding ones, calculated within the harmonic oscillator approximation [3], in average on 5-20\%.

In conclusion let us underline that the developed approach can be considered as the most consistent scheme for sensing new laser-electron-nuclear ef- 
fects in diatomic molecus and in general molecular systems. It is obvious that a direct experimental observation of the laser electron-nuclear and electronvibration-rotation-nuclear effects $\left(\mathrm{H}^{79} \mathrm{Br}, \mathrm{H}^{127} \mathrm{I}\right)$ is of a great importance from theoretical point of view as well as different applications, including a construction of new type sensors for tasks of nuclear physics and nuclear technologies.

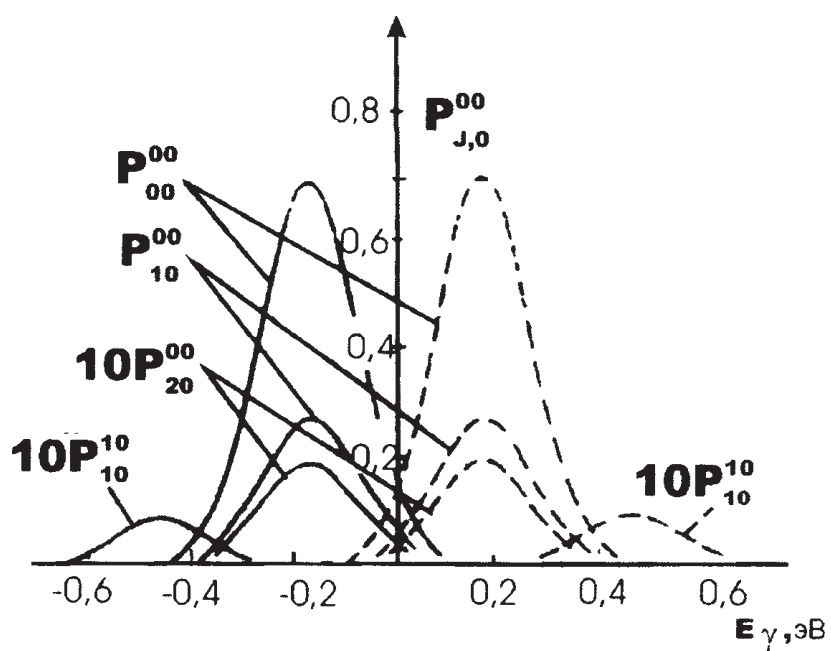

Fig.1. Calculated emission (solid curve) and absorption spectrum of nucleus ${ }^{79} \mathrm{Br}\left(\mathrm{E}_{\gamma}^{(0)}=217 \mathrm{KeV}\right)$ linked with molecule $\mathrm{H}^{79} \mathrm{Br}$. Initial state of molecule $\mathrm{v}_{\mathrm{a}}=0, \mathrm{~J}_{\mathrm{a}}=0$.

Acknowledgements. Author would like to thank Profs. W.Kohn, E.Brändas, I.Kaplan, V.Letokhov, L.Ivanov and A. Glushkov for helpful comments.

\section{References}

1. Letokhov V.S., Laser Spectroscopy. - N. - Y.: Acad.Press, 2001

2. Dykhne A.M., Yudin G.L., Sudden perturbations and quantum evolution. - Moscow: UFN, 1996.

3. Goldansky V.I., Letokhov V.S. Effect of laser radiation on nuclear decay processes// Sov. Phys. JETP. - 1974. - Vol.67. - P.513-516.

4. Letokhov V.S., Minogin V.G., Spectrum of gamma-transitions of the nucleus in diatomic molecule//JETP. — 1985. - Vol. 69(5). — P.15681578.

5. Ivanov L.N., Letokhov V.S. Possibility of discharge of metastable nuclei during negative muon capture// Sov.Phys. JETP. — 1976. Vol.70-P.19-28.

6. Ivanov L.N., Letokhov V.S. Spectroscopy of autoionization resonances in heavy elements atoms// Com.Mod.Phys.D.:At.Mol.Phys. - 1985. — Vol.4. - P.169-184.

7. Glushkov A.V., Ivanov L.N. Radiation Decay of Atomic States: atomic residue and gauge non- invariant contributions // Phys. Lett.A. — 1992. Vol.170,N1. - P.33-37.

8. Wauters L., Vaeck, N. Study of the electronic rearrangement induced by nuclear transmutations: A B-spline approach applied to the beta decay of ${ }^{6} \mathrm{He}$ // Phys.Rev.C. - 1996. — Vol.53. - P.497-502..

9. Wauters L., Vaeck N., Godefroid M., van der Hart H.W., Demeur M., Recoil-induced electronic excitation and ionization in one-and two-electron ions// J.Phys. B. - 1997. — Vol.30 — P.4569-4589.

10. Harston M.R., Carroll J.J., Nuclear excitation and de-excitation in resonant electronic transitions// Laser Phys. - 2004. - Vol.14. - P.1452-1463.

11. Glushkov A.V., Malinovskaya S.V., Co-operative laser nuclear processes: border lines effects// In: New projects and new lines of research in nuclear physics. Eds. G.Fazio and F.Hanappe, Singapore : World Scientific. - 2003. - P.242-250.

12. Malinovskaya S.V., QED calculation of cooperative electron - nuclear processes: the electron-nuclear $\mathrm{g}$ transition spectra of nucleus in the multi-charged ion $\mathrm{FeXIX//Progress}$ of Theor. Phys. and Chem. - 2005. - Vol.41. - P.351-358.

13. Malinovskaya S.V., Cooperative laser-electronnuclear processes: QED calculation of a spectrum of electron-nuclear g-transitions of a nucleus in the neutral atom // Int.Journ.Quant.Chem. — 2005. Vol.104, N4 . - P. 486-490.

14. Malinovskaya S.V., Consistent quantum approach to new laser-electron-nuclear photo phenomena in molecules: diatomics// Photoelectronics. - 2005. — Vol.14. - P.95-100.

15. Glushkov A.V., Malinovskaya S.V., Prepelitsa G.P., Ignatenko V.M., Manifestation of the new laser-electron nuclear spectral effects in thermalized plasma: QED theory of cooperative laser-electron- nuclear processes// J.Phys.CS. 2005. - Vol.11. - P.199-206.

16. Glushkov A.V., Malinovskaya S.V., Svinarenko A.A., Chernyakova Yu.G., QED Calculation of Electron Satellites Spectra in Intense Laser Field in Multicharged Ion//Int.J.Quant.Chem. - 2004. Vol.99,N5. - P.673-678.

17. Glushkov A.V., Malinovskaya S.V., Dubrovskaya Y., Sensing the atomic chemical composition effect on the b decay probabilities// Sensor Electr. \& Microsyst. Techn. - 2004. - N3. - P.31-35.

18. Glushkov A.V., Malinovskaya S.V., New approach to construction of the effective potential of valent electrons// Sov.J.Phys.Chem. — 1988. Vol.62(1). - P.100-106.

19. Glushkov A.V., Malinovskaya S.V., Dudnik N.N., Perturbation theory with model zeroth approximation for molecules//Sov.J.Struct.Chem. - 1988. - Vol.29. - P.163-168.

20. Simons G., Parr R.G., Quantum Chemistry. - NY.: Acad.Press, 2002. 